\title{
Effects of eye cover among high risk neonates at night shift on their distress levels
}

\author{
Eman Ali Moselhi Mater*1, Huda Shawky Mahamud ${ }^{2}$, Mohamed Farouk Mohamed ${ }^{3}$ \\ ${ }^{1}$ Pediatric Nursing Department, Faculty of Nursing, Cairo University, Egypt \\ ${ }^{2}$ Pediatric Nursing Department, Faculty of Nursing, Helwan University, Egypt \\ ${ }^{3}$ Pediatrics and Neonatology, Faculty of Medicine, Cairo University, Egypt
}

Received: November 26, 2018

DOI: $10.5430 /$ jnep.v9n7p9
Accepted: January 29, $2019 \quad$ Online Published: March 20, 2019

URL: https://doi.org/10.5430/jnep.v9n7p9

\begin{abstract}
Background and aim: The Neonatal Intensive Care Unit (NICU) is a stressful environment for high risk neonates. Persistent bright light is one of the main environmental stressors that are distressed newborn infants in NICU. Cycled lighting may decrease distress level of newborn infants by enhancing calming status. This study aimed to investigate effects of eye cover among high risk neonates at night shift on their distress levels.

Methods: Quasi experimental research design was carried out on a randomized sample of 60 newborn infants attending the NICU of El Manial University Hospital (Kasr Al Ainy), (30 control group and 30 study group). Neonatal assessment tool and COMFORTneoNRS scale were utilized for data collection.

Results: There was a statistically significant difference between control and study groups regarding the distress levels $(p<.00)$. The mean score of distress levels were $6.80 \pm 1.80$ and $0.80 \pm 1.15$ respectively and the mean score of comfort levels in the newborn infants in the control and study groups were $23.22 \pm 5.50$ and $6.60 \pm 1.06$ respectively. Eye coved enhanced quite sleep $(66.7 \%)$, relaxed muscle $(73.3 \%)$, decrease movement $(66.7 \%)$ and no crying $(85.7 \%)$.

Conclusions: The use of eye cover among high risk neonates at night shift is effective to decrease their distress level and improve their comfort state in the morning shift by promoting quite sleep and relaxation. Recommendations: The educational program is needed to raise awareness among neonatal nurses about the effect of light reduction methods such as eye patches on the distress level and comfort state that enhances the growth and development of newborn infants.
\end{abstract}

Key Words: Eye patches, Newborn infants, NICU, Comfort state, Distress level

\section{INTRODUCTION}

High risk neonates in the Neonatal Intensive Care Unit (NICU) are exposed to high intensity lighting level that triggers signs of stress. ${ }^{[1]}$ Preterm infants eyelids are very thin and may not be strong enough to keep it closed for prolonged periods of times that allow light to pass through. Also, they may be unable to communicate with their discomfort. ${ }^{[2]}$ Exposure to high level of light increased stress levels of seriously ill newborn infants. ${ }^{[3,4]}$ Bright light is one of the contributing environmental factors of stress and affected stress coping mechanism. ${ }^{[5,6]}$

Consistent bright light levels in NICU may have negative effects on the growth and development on newborn infants. ${ }^{[3,7]}$ It could disturb or delay the development of circadian rhythms that cause poor growth and sleep disturbances. ${ }^{[8]}$ A circadian rhythm is any biological process that regulates the timing of biological processes and daily behavior during 24 hours. ${ }^{[9]}$ It is normally entrained through

\footnotetext{
*Correspondence: Eman Ali Moselhi Mater; Email: moselhibasmala11@yahoo.com; Address: Nursing Department, Faculty of Nursing, Cairo University, Egypt. 
natural exposure to light during the day and to darkness during the night over a 24 hour period. ${ }^{[10]}$

Newborn infants have essential needs rest at night and activity during day. ${ }^{[1]}$ According to Roy's adaptation model, nurses should avoid stress factors by controlling light in the NICU that may help newborn infants to adapt with their environment. ${ }^{[1,2,12-14]}$ Nightingale's theory stated that cycled light environment is light in the day and the darkness at night that creates a day/night rhythm that supports human life. ${ }^{[15]}$ Newborn infants can be shielded from exposure to constant light conditions of the NICU while simultaneously allowing medical care staff to visually monitor newborn infants adequately. ${ }^{[16]}$

The Neonatal Individualized Developmental Care and Assessment Program (NIDCAP) reported that reducing exposure to light by covering the incubator didn't improve important short or long term outcomes and recommended to use other methods of light controlling methods. The American Academy of Pediatrics and the American College of Obstetricians and Gynecologists recommend neonatal care should be under cycled lighting conditions. ${ }^{[17]}$ A Cochrane Systematic Review shows the benefit of cycled light that promote circadian rhythms and enhance growth and development. ${ }^{[18]}$ Care strategies to reduce newborn infants stress in the neonatal intensive care unit by decreasing light levels in the environment may ensure physical and emotional stability. ${ }^{[19]}$

In Egypt, there are scarce researches conducted to evaluate the effect of light reduction methods such as cycle light by covering eyes of new born infants. After birth, high risk neonates are cared in an environment that has no planned cycle light. They are exposed to continuous bright light, continuous near darkness or an unstructured combination of them. Based on the knowledge concerning light and its importance to circadian rhythm and distress level of newborn infants, the current study was conducted to investigate effects of eyes cover among high risk neonates at night shift on their distress levels. Hopefully the findings of current study would help newborn infants to overcome the distress level and providing evidence based data that can develop the neonatal nursing practice and research.

\section{Hypothesis}

High risk neonates who have eye covers at night shift will have a significant lower distress scores than control group.

\section{MethodS}

\subsection{Research design}

Quasi experimental design was utilized to accept or reject research hypothesis.

\subsection{Sample and sample size}

Randomized sample of 60 newborn infants was selected according to the following inclusion criteria: gestational age from 30 to $<37$ weeks, conscious and both sexes. Exclusion criteria included newborn infants with severs neonatal sepsis and congenital anomalies (central nervous system and cardiovascular system) Simple Random Sample was used by using a SPSS program. 60 newborn infants randomly assigned into two groups, study group (covered eyes) (30) and control group (30) who received ambient bright light (see Figure 1). To determine a sample size, a power analysis was conducted using 0.05 as the level of significance, 0.95 as the power and effect size of 0.25 . The minimum required sample size obtained was 60 preterm infants.

\subsection{Ethical consideration}

Prior to data collection, permission was obtained from the research scientific board of hospital, the head of NICUs and faculty of nursing, Cairo University. The parents of newborn infants gave informed verbal consent prior to their newborn infants' participation in the study. The participation was voluntary.

\subsection{Setting}

The study was conducted at the Neonatal Intensive Care Unit at El Manial University Hospital (Kasr Al Ainy).

\subsection{Instruments}

(1) Neonatal assessment tool was developed by researcher to collect data about newborn infant's characteristics such as birth weight, gestational age, Apagr score, diagnosis, mode of delivery, hospital stay.

(2) COMFORTneoNRS scale, adopted Dijk et al. (2009). It is currently the most validated clinical test to determine the level of distress and comfort in infants admitted to NICU. Numeric Rating Scale (NRS) for distress is associated with COMFORTneo that help researchers to measure distress level by NRS. Rating is on a scale from 0 to 10 ( 0 represents no distress and 10 is worst distresses). Scores 1 to 3 are considered mild distress, 4 to 6 moderate distress and 7 to 10 sever distress. It measured after COMFORTneo that consists of 6 items; Alertness, Calmness/agitation, Respiratory Response or Crying, Movement, Facial Tension and Muscle Tone. Responses are on a 1 to 5 Likert scale, total scores range from 6 to 30 , the lowest score in the scale is 6 and the highest is 30 . High scores indicate that the newborn infant is uncomfortable. ${ }^{[20,21]}$

(3) Eye patches was covered newborn infants' eyes at night shift from $10 \mathrm{pm}$ to 8 am to protect them from constant light (eye patches like used during phototherapy).

ISSN 1925-4040 E-ISSN 1925-4059 


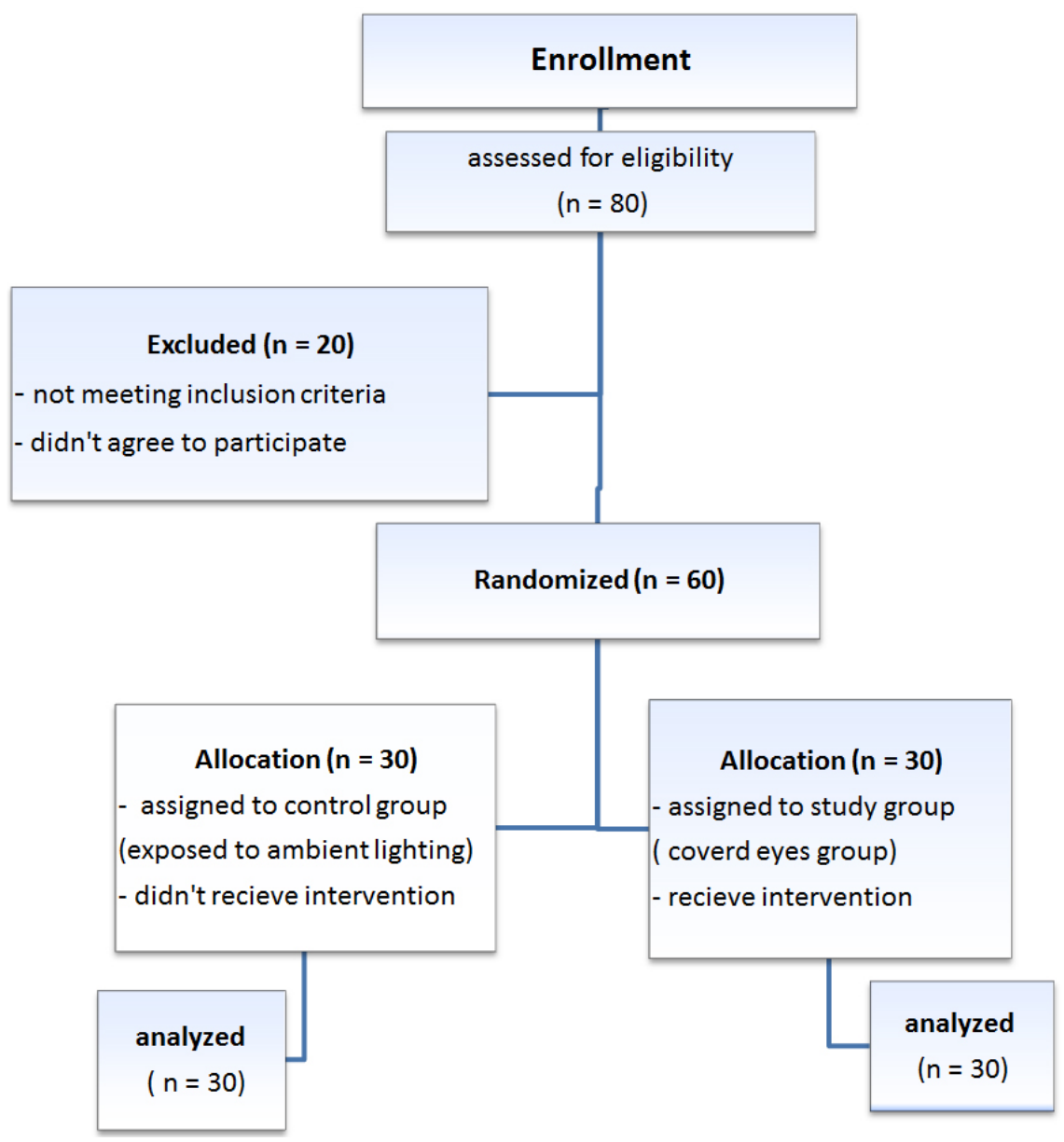

Figure 1. Selection of the study participants

\subsection{Pilot study}

A pilot study was carried out on $10 \%$ of sample size (6 newborn infants) to ensure the clarity, applicability of the tools, test feasibility of the study and estimate sample size and the time needed for data collection. The result of pilot study confirmed that the study was feasible. The sample of the pilot study was excluded from the total sampling.

\subsection{Validity and reliability}

The newborn assessment tool was submitted to a panel of five experts in the field of high risk neonates to examine the content validity (covering, clarity, wording, length, format and overall appearance). Minor modification was performed. COMFORTneoNRS scale was valid and reliable professional tool (Cronbach alpha was 0.88$).{ }^{[20,22]}$

\subsection{Procedure}

Upon receiving the formal approval from the Research Scientific Board of hospital, the head of NICUs and faculty of nursing, Cairo university and the parents verbal consent. Data was collected through a period of 8 months from September, 2017 to April, 2018. Newborn infant's characteristics were recorded from the medical sheet. Simple randomization was done by using SPSS program. The sample of the study consisted of 60 newborn infants randomly assigned into two groups, study group (covered eyes) (30) and control group (30). Eye patches was used to cover eyes of newborn infants at night shift from $10 \mathrm{pm}$ to 8 am to protect them from persistent ambient light (eye patches like used during phototherapy) to enhance light dark cycling at night shift (10 hours) for 10-15 days but control group received persistent ambient light. The distress and comfort levels were assessed by assessors (researcher and two expert nurses) by using English version of COMFORTneoNRS scale after 10 days in the morning shift at 9 am to control confounding factors such as different days and chronological age. After that, the researchers recorded the mean of the three readings and calculated the mean of distress score according to scoring system.

\subsection{Data analysis}

The Statistical Package for the Social Science (SPSS) version 20.0 was utilized for data entry, tabulation and analysis. Descriptive statistics were computed to summarize the new- 
born infant's characteristics. The independent T test was used to compare means and Chi Square was used to compare categorical variables

\section{RESULT}

Table 1 and Figure 2 indicated that there was no statistically significant difference between control and study group (covered eyes) regarding to newborn infants' characteristics. The mean of gestational age was $29.80 \pm 9.39$ weeks and 32.36 \pm 6.38 weeks respectively, the mean of birth weight was $1,924.7 \pm 726.2$ grams and 2,028.6 \pm 902.3 grams respectively, Apgar score in 10 minute was $8.86 \pm 1.27$ and 8.76 \pm 1.19 , more than half of them diagnosed as respiratory distress $(60 \%$ and $56.7 \%$ respectively). Around one third of them connected with mechanical ventilator $(33.3 \%$ and $40 \%$ respectively).

Table 1. Newborn infant's characteristics in percentage distribution $(n=60)$

\begin{tabular}{|c|c|c|c|c|c|c|}
\hline \multirow[t]{2}{*}{ Characteristics } & \multicolumn{2}{|c|}{$\begin{array}{l}\text { Control group } \\
(n=30)\end{array}$} & \multicolumn{2}{|c|}{$\begin{array}{l}\text { Covered eye group } \\
(n=30)\end{array}$} & \multirow{2}{*}{$\begin{array}{l}\text { Chi square } \\
\text { test }\end{array}$} & \multirow[t]{2}{*}{$p$ value } \\
\hline & No & $\%$ & No & $\%$ & & \\
\hline $\begin{array}{l}\text { Gender } \\
\text { Male } \\
\text { Female }\end{array}$ & $\begin{array}{l}20 \\
10\end{array}$ & $\begin{array}{l}66.7 \\
33.3\end{array}$ & $\begin{array}{l}14 \\
16\end{array}$ & $\begin{array}{l}46.7 \\
53.3\end{array}$ & 2.443 & .118 \\
\hline $\begin{array}{l}\text { Mode of delivery } \\
\text { Normal vaginal delivery } \\
\text { Cesearn section }\end{array}$ & $\begin{array}{l}15 \\
15\end{array}$ & $\begin{array}{l}50 \\
50\end{array}$ & $\begin{array}{l}10 \\
20\end{array}$ & $\begin{array}{l}33.3 \\
66.7\end{array}$ & 1.714 & .190 \\
\hline $\begin{array}{l}\text { Diagnosis } \\
\text { Respiratory Distress } \\
\text { Hyperbilirubinaemia } \\
\text { Low birth weight }\end{array}$ & $\begin{array}{l}17 \\
5 \\
8\end{array}$ & $\begin{array}{l}56.7 \\
16.7 \\
26.7\end{array}$ & $\begin{array}{l}18 \\
7 \\
5\end{array}$ & $\begin{array}{l}60 \\
23.3 \\
16.7\end{array}$ & 1.054 & .590 \\
\hline $\begin{array}{l}\text { Gestational age ( weeks) } \\
30-33 \\
34<37 \\
>37\end{array}$ & $\begin{array}{l}22 \\
4 \\
4\end{array}$ & $\begin{array}{l}73.4 \\
13.3 \\
13.3\end{array}$ & $\begin{array}{l}15 \\
8 \\
7\end{array}$ & $\begin{array}{l}50 \\
26.7 \\
23.3\end{array}$ & 4.637 & .327 \\
\hline Variable & \multicolumn{4}{|c|}{ Mean \pm SD } & T. test & $p$ value \\
\hline Gestational age (weeks) & \multicolumn{2}{|c|}{$29.80 \pm 9.39$} & \multicolumn{2}{|c|}{$32.36 \pm 6.38$} & 1.238 & .22 \\
\hline Birth weight (gram) & \multicolumn{2}{|c|}{$1,924.7 \pm 726.2$} & \multicolumn{2}{|c|}{$2,028.6 \pm 902.3$} & 0.492 & .625 \\
\hline Weight at observation (gram) & \multicolumn{2}{|c|}{$2,425.3 \pm 2,290.2$} & \multicolumn{2}{|c|}{$3,519 \pm 4,152.3$} & -1.26 & .213 \\
\hline Apgar score 1 min & \multicolumn{2}{|c|}{$4.16 \pm 2.40$} & \multicolumn{2}{|c|}{$3.60 \pm 2.09$} & -0.973 & .335 \\
\hline Apgar score 5 min & \multicolumn{2}{|c|}{$6.83 \pm 1.76$} & \multicolumn{2}{|c|}{$7.10 \pm 1.82$} & -0.575 & .567 \\
\hline Apgar score $10 \mathrm{~min}$ & \multicolumn{2}{|c|}{$8.76 \pm 1.19$} & \multicolumn{2}{|c|}{$8.86 \pm 1.27$} & -0.313 & .755 \\
\hline Hospital stay & \multicolumn{2}{|c|}{$10.06 \pm 3.92$} & \multicolumn{2}{|c|}{$12.83 \pm 8.82$} & 1.569 & .122 \\
\hline
\end{tabular}

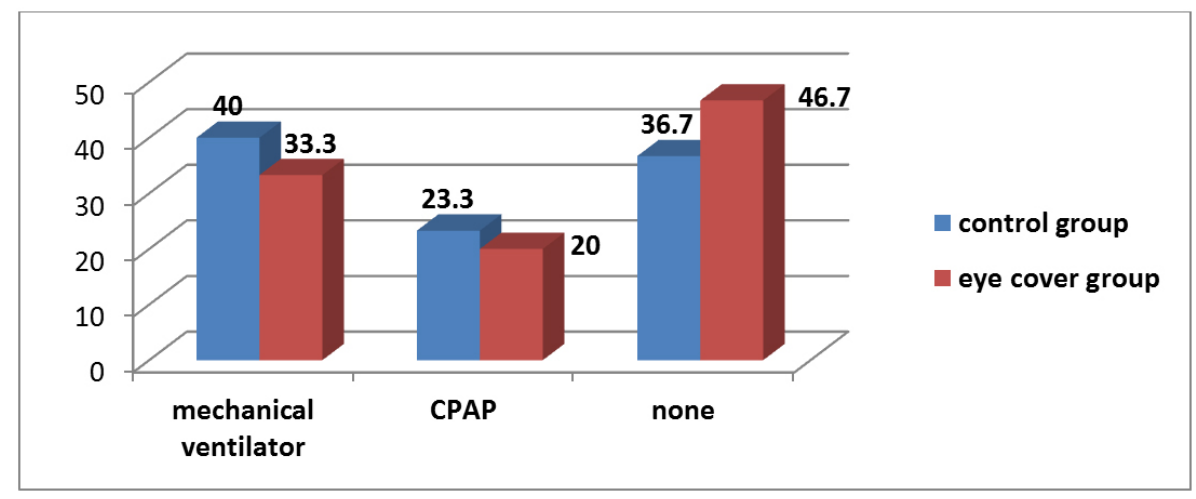

Figure 2. Percentage distribution of newborn infants according to their respiratory support methods in covered eyes and control groups $(n=60)$ 
Table 2 revealed that there was a significant difference be- fants in the control and study group (covered eyes) were 6.80 tween control and study group (covered eyes) regarding dis- \pm 1.80 and $0.80 \pm 1.15$ respectively and the mean score of tress level of newborn infants in the morning shift. Slightly more than half of newborn infants $(56.7 \%)$ had worst distress in the control group and no distress in study group (covered eyes). The mean score of distress level in the newborn incomfort level in the newborn infants in the control and study group (covered eyes) were $23.22 \pm 5.50$ and $6.60 \pm 1.06$ respectively.

Table 2. The effect of eye cover on the distress level of newborn infants according to COMFORTneoNRS distress scale in relation to the control group $(n=60)$

\begin{tabular}{|c|c|c|c|c|c|c|c|}
\hline \multirow{2}{*}{$\begin{array}{l}\text { Total score of } \\
\text { COMFORTneoNRS }\end{array}$} & \multicolumn{2}{|c|}{$\begin{array}{l}\text { Control group } \\
(n=30)\end{array}$} & \multicolumn{2}{|c|}{$\begin{array}{l}\text { Covered eyes group } \\
(n=30)\end{array}$} & \multirow{2}{*}{$\begin{array}{l}\text { Chi } \\
\text { square } \\
\text { test }\end{array}$} & \multirow{2}{*}{$\begin{array}{l}\text { T } \\
\text { Test }\end{array}$} & \multirow{2}{*}{$p$ value } \\
\hline & No & $\%$ & No & $\%$ & & & \\
\hline \multicolumn{8}{|l|}{ Distress levels } \\
\hline No distress & & & 17 & 56.7 & & & \\
\hline Mild distress (1-3) & & & 11 & 36.7 & 53.06 & & \\
\hline Moderate distress (4-6) & 13 & 43.3 & 2 & 6.7 & & & $.00 *$ \\
\hline Sever distress $(7-10)$ & 17 & 56.7 & & & & & \\
\hline Mean \pm SD & \multicolumn{2}{|c|}{$6.80 \pm 1.80$} & \multicolumn{2}{|c|}{$0.80 \pm 1.15$} & & -15.31 & \\
\hline Mean of comfort level & \multicolumn{2}{|c|}{$23.22 \pm 5.50$} & \multicolumn{2}{|c|}{$6.60 \pm 1.06$} & & 16.1 & \\
\hline
\end{tabular}

Table 3 illustrated that there was a significant difference of them were awake and hyper alert (33.3\%) in the control between control and study group (covered eyes) regarding group and two thirds of them was quiet sleep in study group alertness of newborn infants in the morning shift, one third (covered eyes) (66.7\%).

Table 3. The effect eye cover on the alertness of newborn infants according to COMFORTneoNRS scale in relation to the control group $(\mathrm{n}=60)$

\begin{tabular}{|c|c|c|c|c|c|c|}
\hline \multirow{2}{*}{ Alertness } & \multicolumn{2}{|c|}{$\begin{array}{l}\text { Control group } \\
(\mathrm{n}=30)\end{array}$} & \multicolumn{2}{|c|}{$\begin{array}{l}\text { Covered group } \\
(n=30)\end{array}$} & \multirow{2}{*}{$\begin{array}{l}\text { Chi } \\
\text { square } \\
\text { test }\end{array}$} & \multirow{2}{*}{$p$ value } \\
\hline & No & $\%$ & No & $\%$ & & \\
\hline Quiet sleep & & & 20 & 66.7 & & \\
\hline Active sleep & & & 8 & 26.7 & & \\
\hline Quietly awake & 11 & 36.7 & 2 & 6.7 & 53.231 & $.00 *$ \\
\hline Actively awake & 9 & 30 & & & & \\
\hline Awake and hyper alert & 10 & 33.3 & & & & \\
\hline
\end{tabular}

Table 4 showed that there was a significant difference between control and study group (covered eyes) regarding calmness/agitation of newborn infants in the morning shift, $43.3 \%$ of them were anxious in the control group and $63.3 \%$ of them were calm in study group (covered eyes).

Tables 5 and 6 revealed that there was a significant difference between control and study group (covered eyes) regarding respiratory response (ventilated baby) and crying (non-ventilated baby) in the morning shift, more than half of ventilated babies (52.6\%) were actively breathes against ventilator or coughs regularly in the control group and 50\% of them were spontaneous respiration on ventilator in study group (covered eyes).The majority of non-ventilated babies were intense crying or screaming $(72.7 \%)$ in the control group and $85.7 \%$ of were no cry in study group.

Tables 7 and 8 revealed that there was a significant difference between control and study group (covered eyes) regarding facial tension and body movement in the morning shift. Around half of newborn infant's facial tension signs $(46.7 \%)$ were continuous eye squeeze and brow furrow in the control group but $70 \%$ of them were fully relaxed facial muscle and relaxed open mouth in study group (covered eyes). Regarding 
body movement, $40 \%$ of newborn infants had more than three vigorous arm or/and leg movements or whole body in the control group but two third of them had no or minimum movement in the study group (covered eyes).

Table 9 indicated that there was a significant difference be- tween control and study group (covered eyes) regarding body muscle tone in the morning shift, the majority of newborn infants $(70 \%)$ had increased muscle tone (clenched hand and or clenched and bent toes) in the control group and $73.3 \%$ of them had fully relaxed muscle in study group (covered eyes).

Table 4. The effect of eye cover on the calmness/agitation of newborn infants according to COMFORTneoNRS scale in relation to the control group $(n=60)$

\begin{tabular}{|c|c|c|c|c|c|c|}
\hline \multirow{2}{*}{ Calmness/Agitation } & \multicolumn{2}{|c|}{ Control group $(n=30)$} & \multicolumn{2}{|c|}{ Covered eyes group $(n=30)$} & \multirow{2}{*}{$\begin{array}{l}\text { Chi square } \\
\text { test }\end{array}$} & \multirow{2}{*}{$p$ value } \\
\hline & No & $\%$ & No & $\%$ & & \\
\hline Calm & & & 19 & 63.3 & & \\
\hline Slightly anxious & & & 10 & 33.3 & & \\
\hline Anxious & 13 & 43.3 & 1 & 3.3 & 56.286 & $.00 *$ \\
\hline Very anxious & 9 & 30 & & & & \\
\hline Panicky & 8 & 26.7 & & & & \\
\hline
\end{tabular}

Table 5. The effect of eye cover on the respiratory response of newborn infants according to COMFORTneoNRS scale in relation to the control group $(\mathrm{n}=35)$

\begin{tabular}{|c|c|c|c|c|c|c|}
\hline \multirow{2}{*}{$\begin{array}{l}\text { Respiratory response } \\
\text { (ventilated baby) }\end{array}$} & \multicolumn{2}{|c|}{$\begin{array}{l}\text { Control group } \\
(\mathrm{n}=19)\end{array}$} & \multicolumn{2}{|c|}{$\begin{array}{l}\text { Covered eyes group } \\
(n=16)\end{array}$} & \multirow{2}{*}{$\begin{array}{l}\text { Chi } \\
\text { square } \\
\text { test }\end{array}$} & \multirow[t]{2}{*}{$p$ value } \\
\hline & No & $\%$ & No & $\%$ & & \\
\hline No spontaneous respiration & & & 6 & 37.6 & & \\
\hline Spontaneous respiration on ventilator & 1 & 5.3 & 8 & 50 & & \\
\hline Unrest or resistance to ventilator & 2 & 10.6 & 1 & 6.2 & 25.50 & $.00 *$ \\
\hline Actively breathes against ventilator or coughs regularly & 10 & 52.6 & 1 & 6.2 & & \\
\hline Fights ventilator & 6 & 31.5 & & & & \\
\hline
\end{tabular}

Table 6. The effect of covered eyes on the crying types of newborn infants according to COMFORTneoNRS distress scale scale in relation to the control group $(n=25)$

\begin{tabular}{|c|c|c|c|c|c|c|}
\hline \multirow{2}{*}{$\begin{array}{l}\text { Cry } \\
\text { (non ventilated baby) }\end{array}$} & \multicolumn{2}{|c|}{ Control group $(n=11)$} & \multicolumn{2}{|c|}{ Eye cover group $(n=14)$} & \multirow{2}{*}{$\begin{array}{l}\text { Chi square } \\
\text { test }\end{array}$} & \multirow{2}{*}{$p$ value } \\
\hline & No & $\%$ & No & $\%$ & & \\
\hline No crying & & & 12 & 85.7 & & \\
\hline Faint crying & & & 2 & 14.3 & & \\
\hline Soft crying or moaning & & & & & 25.257 & $.00 *$ \\
\hline Hard crying & 3 & 27.3 & & & & \\
\hline Intense crying or Screaming & 8 & 72.7 & & & & \\
\hline
\end{tabular}

Table 7. The effect of eye cover on the facial tension of newborn infants according to COMFORTneoNRS distress scale in relation to the control group $(n=60)$

\begin{tabular}{|c|c|c|c|c|c|c|}
\hline \multirow{2}{*}{ Facial tension } & \multicolumn{2}{|c|}{ Control group $(\mathrm{n}=30)$} & \multicolumn{2}{|c|}{ Covered eyes group $(n=30)$} & \multirow{2}{*}{$\begin{array}{l}\text { Chi square } \\
\text { test }\end{array}$} & \multirow{2}{*}{$p$ value } \\
\hline & No & $\%$ & No & $\%$ & & \\
\hline Facial muscle fully relaxed, relaxed open mouth & & & 21 & 70 & & \\
\hline Normal facial tension & & & 6 & 20 & & \\
\hline Intermittent eye squeeze and brow furrow & 11 & 36.7 & 3 & 10 & 50.571 & $.00 *$ \\
\hline Continuous eye squeeze and brow furrow & 14 & 46.7 & & & & \\
\hline Facial muscles contorted and grimacing & 5 & 16.7 & & & & \\
\hline
\end{tabular}

${ }^{*} p<.00$ 
Table 8. The effect of eye cover on the body movements of newborn infants according to COMFORTneoNRS distress scale in relation to the control group $(n=60)$

\begin{tabular}{|c|c|c|c|c|c|c|}
\hline \multirow[t]{2}{*}{ Body movement } & \multicolumn{2}{|c|}{$\begin{array}{l}\text { Control group } \\
(\mathrm{n}=30)\end{array}$} & \multicolumn{2}{|c|}{$\begin{array}{l}\text { Covered eyes } \\
\text { group }(n=30)\end{array}$} & \multirow{2}{*}{$\begin{array}{l}\text { Chi } \\
\text { square } \\
\text { test }\end{array}$} & \multirow[t]{2}{*}{$p$ value } \\
\hline & No & $\%$ & No & $\%$ & & \\
\hline No or minimum movement & & & 20 & 66.7 & & \\
\hline Up to three slight arm and or leg movements & & & 9 & 30 & & \\
\hline More than three slight arm and or leg movements & 12 & 40 & 1 & 3.3 & 56.30 & $.00 *$ \\
\hline Up to three vigorous arm and or leg movements & 6 & 20 & & & & \\
\hline More than three vigorous arm and or leg movements or whole body & 12 & 40 & & & & \\
\hline
\end{tabular}

Table 9. The effect of eye cover on the body muscle tone of newborn infants according to COMFORTneoNRS distress scale in relation to the control group $(n=60)$

\begin{tabular}{|c|c|c|c|c|c|c|}
\hline \multirow{2}{*}{ Body muscle tone } & \multicolumn{2}{|c|}{$\begin{array}{l}\text { Control group } \\
(n=30)\end{array}$} & \multicolumn{2}{|c|}{$\begin{array}{l}\text { Covered eyes } \\
\text { group }(n=30)\end{array}$} & \multirow{2}{*}{$\begin{array}{l}\text { Chi } \\
\text { square } \\
\text { test }\end{array}$} & \multirow{2}{*}{$p$ value } \\
\hline & No & $\%$ & No & $\%$ & & \\
\hline Muscles fully relaxed (open hands, dribbling, open mouth) & & & 22 & 73.3 & & \\
\hline Reduced muscle tone, less resistance than normal & & & 7 & 23.3 & & \\
\hline Normal muscle tone & 3 & 10 & 1 & 3.3 & 57.00 & $.00 *$ \\
\hline Increased muscle tone (clenched hands and or clenched, bent toes) & 21 & 70 & & & & \\
\hline Extreme muscle tone (rigidity and flexion of fingers and or toes) & 6 & 20 & & & & \\
\hline
\end{tabular}

\section{DisCUSSION}

The current study results showed that high risk neonates who have eye covers at night shift had a significant lower distress scores than control group, there was a statistically significant difference between control and study group (covered eyes) regarding the mean score of distress level and comfort state. No study reported on our essential results of distress level and eye cover as a method for cycled light. Results from other studies strengthen our findings by describing some distress items in COMFORTneoNRS scale like alert/sleep, respiratory response, crying, activity, facial tension and body movements. Cochrane Data Base of Systematic Review ${ }^{[23]}$ about Cycled light in the intensive care unit of preterm and low birth weight infants reported that cycled light offers an advantage than continuous bright light, mainly resulting in improved sleep and fewer days on the ventilator while, continuous bright light has been related to infant stress as manifested by increased levels of activity, decreased sleep and bradycardia. Also, Ropert et al. ${ }^{[2]}$ studied the update and recommendation of neonatal intensive care unit lighting added that dark lighting shift may reduce stress level of newborn infants. This result is consistent with Roy's adaptation model and Nightingale's theory which nurses avoided stress factors, decreased distress level and supported human life of high risk neonates by controlling light in the NICU.

Published by Sciedu Press
As regards to alertness of newborn infants, there was a statistically significant difference between control and study group (covered eyes), two third of them was quiet sleep in covered eyes group and one third of them were hyper alert in the control group. Evidence indicates that exposure to persistent high level of light are associated with sleep disturbances. ${ }^{[3]}$ Light at night is one known factors impairs melatonin secretion for sleeping. ${ }^{[25]}$ In response to light exposure, alertness levels can increase as a result of suppression of melatonin secretion. ${ }^{[5]}$ Sleep is a crucial human physiological need, which is beneficial to the maturation of the central nervous system. ${ }^{[26]}$ Several supportive interventions have been shown to help stabilize infants and preserve sleep by modifying the NICU environment to reduce light levels. ${ }^{[27]}$ The sleep and wakefulness cycle are the most noticeable rhythm in humans. Previous studies have demonstrated that a light dark cycle has promoted better sleep development than constant light. ${ }^{[11]}$ Reduced lighting may improve sleep cycles. It enables the melatonin hormone to increase during the darkness of the night and gives the patient a better chance of sleeping. ${ }^{[15]}$ Deep quite sleep is facilitated by dark and quiet. ${ }^{[28]}$ Previous studies have demonstrated that a light dark cycle has promoted better sleep development than constant light or constant darkness. ${ }^{[11]}$ 
According to respiratory response (ventilated baby), the study illustrated that there was a significant difference between control and study group (covered eyes), more than half of ventilated babies were actively breathes against ventilator or coughs regularly in the control group and half of them were spontaneous respiration on ventilator in coved eyes group. Sleep disruption is stressful to sick newborn infants in NICU and alter state regulation and physiological stability. ${ }^{[28]}$ Reyhani et al. ${ }^{[29]}$ studied the effect of creating an artificial night on physiological changes in preterm infants reported that light dark cycle infants exhibited improved oxygen saturation and developed a daily melatonin rhythm and concluded that the effect of artificial darking night on physiological stabilization of preterm infants is positive. Also, Lebel et al. ${ }^{[30]}$ reported that cycled lighting may have systematically favored physiological stability of newborn infants.

Regarding crying, the majority of newborn infants were no cry in the study group (covered eyes) and intense crying or screaming in the control group. This results was consistent with Guyer et al. ${ }^{[13]}$ studied cycled light exposure reduces fussing and crying in very preterm infants concluded that cycled lighting conditions in neonatal care have beneficial effects on infant's fussing and crying behavior and growth in the first weeks of life. This study supports the introduction of cycled lighting care in clinical neonatal practice. Garden et al. ${ }^{[28]}$ reported that cycled dark light decreases crying and fusing among sick newborn infants by maintaining uninterrupted sleep that are associated with improved state organization and less crying.

Concerning, body movement the results showed that there was a significant difference between control and study group (covered eyes), two third of newborn infants had no or minimum movement in the covered eyes group than control group. This results in agreement with Lebel et al. ${ }^{[30]}$ who studied effects of cycled lighting versus continuous near darkness on physiological stability and activity level in preterm infants recorded that cycled lighting may have reduced motor activity level in the studies with a continuous bright light comparison group. Also, continuous lighting levels have been associated with increased behavioral stress by muscle tone in newborn infants. ${ }^{[19]}$ High intensity lighting level in NICU triggers signs of stress such as an increase in motor activity level. ${ }^{[1,2]}$ Finally, controlling the lighting in the NICU may decrease motor activity level, maintain physiological stability and sleep..$^{[3,13,14]}$

\section{Limitation}

Interpretation of the results should acknowledge some limitation; measurements of sleep are more objective than other variables and small sample size. Future studies should try to ensure that research should be performed in a facility that will offer an adequate sample size in order to validate findings.

\section{Conclusion}

The finding of the study concluded that the use of eye cover at night shift as a method of cycled lighting is effective to decrease distress level among newborn infants.

\subsection{Recommendation}

Based on the study results, the following recommendations are proposed:

(1) Cycled lighting by using eye cover should be applied as a routine care for high risk neonates.

(2) An educational program is needed to raise awareness among nurses and other health care providers about effects of cycled light on the distress level among high risk neonates.

(3) Further studies needed to evaluate the long term outcomes of using eye cover on the physiological and behavioral states of high risk neonates.

\subsection{Implications in nursing science and practice}

The investigation demonstrated positive effect of eye cover of high risk neonates at night shift on distress and comfort levels in the morning. The study findings are useful to nursing practice.

\section{CONFliCtS OF INTEREST Disclosure}

The authors confirm that there is no conflict of interest and the study was not supported by any grant.

\section{REFERENCES}

[1] Zores C, Dufour A, Pebayle T, et al. Very preterm infants can detect small variations in light levels in incubators. Acta Pediatric. 2015; 104: 1005-1011.

[2] Graven SN. Early visual development: implications for the neonatal intensive care unit and care. Clinical Perinatol. 2011; 38(4): 671-
683. PMid:22107897 https://doi.org/10.1016/j.clp. 2011 .08 .006

[3] Pickler R, Grath J, Reyna A, et al. Effects of the neonatal intensive care unit environment on Research and Reports in Neonatology. 2013; 3: $15-20$.

[4] European Standards ICU Lighting. Dynamic lighting as a tool to 
influence the day night rhythm of clients with psychogeriatric. 2011.

[5] Stephenson M, Schroder M, Gilles B, et al. Complex interaction of circadian and non-circadian effects of light on mood: Shedding new light on an old story. Sleep Medicine Reviews. 2012; 16(5): 445-454. PMid:22244990 https ://doi.org/10.1016/j.smrv. 2011.09 .002

[6] Grunau RE. Neonatal pain in very preterm infants: long-term effects on brain, neurodevelopment and pain reactivity. Rambam Maimonides Medical Journal. 2013; 4(4): e0025.

[7] Barrios J, Martínez B, Granados A, et al. A light/dark cycle in the NICU accelerates body weight gain and shortens time to discharge in preterm infants. Early Human Development. 2014; 90(9): 535-540.

[8] Morag I, Ohlsson A. Cycled light in the Intensive Care unit for Preterm and Low Birth Weight Infants (Review). Cochrane Database of Systematic Reviews. John Wiley \& Sons; 2017.

[9] Edgar R, Green E, Zhao Y, et al. Peroxiredoxins are conserved markers of circadian rhythms. Nature J. 2012; 485(7399): 459-464. PMid:22622569 https://doi.org/10.1038/nature11088

[10] Hankins M, Peirson S, Foster G. Melanopsin: an exciting photopigment. Trends Neuroscience. 2007; 31(1): 27-36. PMid:18054803 https://doi.org/10.1016/j.tins.2007.11.002

[11] Kaneshi Y, Ohta H, Morioka K, et al. Influence of light Exposure at Nighttime on Sleep Development and Body Growth of Preterm Infants. Scientific Reports. 2016; 6(21): 680.

[12] Roy SC. The Roy Adaptation Model. 3rd ed. Upper Saddle River. NJ: Pearson. 2009.

[13] Guyer C, Huber R, Fontijn J, et al. Cycled light exposure reduces fussing and crying in very preterm infants. Pediatrics. 2012; 130(1): e145-e151.

[14] Vasquez S, Barrios JA, Narváez P, et al. Light/dark cycle in the NICU accelerates body weight gain and shortens time to discharge in preterm infants. Early Human Development. 2014; 90(9): 535-548. PMid:24831970 https://doi .org/10.1016/j. earlhumdev. 2 014.04 .015

[15] Engwall A, Fridh I, Bergbom I, et al. Let There Be Light and Darkness Findings From a Prestudy Concerning Cycled Light in the Intensive Care Unit Environment. Critical Care Nursing. 2014; 37(3): 273298. PMid:24896559 https://doi.org/10.1097/CNQ. 000000 0000000031

[16] Watanabe S, Akiyama S, Hanita T, et al. Designing artificial environments for preterm infants based on circadian studies on pregnant uterus. Frontiers in Endocrinology. 2013.
[17] Ohlsson A, Jacobs SE. NIDCAP: a systematic review and metaanalyses of randomized control trials. Pediatrics. 2013; 131(3): e881.

[18] Morag I, Ohlsson A. Cycled light in the intensive care unit for preterm and low birth weight infants. Cochrane Database Syst Rev; 2011.

[19] Philips Y. Management of Neonatal Stress \& Pain. Phillips health care education. Koninklijke Philips. 2014; 1-5.

[20] Dijk K, Roofthooft D, Anand K, et al. Taking Up the Challenge of Measuring Prolonged Pain in (Premature) Neonates The COMFORTneo Scale. Promising Clinical Journal of Pain. 2009; 25(7): 607-616. PMid:19692803 https://doi.org/10.1097/AJP.0b013e3181 a5b52a

[21] Kahraman A, Basbakkal Z, Yalaz M, et al. The effect of Nesting Position on Pain, Stress and Comfort during Heel Lance in Premature Infants. Pediatric Neonatology. 2017; 59(4): 352-359.

[22] Hockenberry M, Wilson D, Roger S. Wong's Nursing Care of Infants and Children. 11th ed. El Sevier, Evolve; 2019.

[23] Cochrane Database Systematic Review. Cycled light in the intensive care unit for preterm and low birth weight infants. 2011.

[24] Roberto G, Rodríguez A, Andrea E, et al. Neonatal intensive care unit lighting: update and recommendations. Arch Argent Pediatric. 2016; 114(4): 361-367.

[25] Kamdar B, Needham D, Collop N. Sleep Deprivation on Critical Illness; Its Role in Physiological Recovery. Intensive Care Medicine Journal. 2012; 27: 97-111. PMid:21220271 https : //doi .org/10 $.1177 / 0885066610394322$

[26] Peigneux P, Fogel S, Smith C. Memory processing in relation to sleep. Principles \& Practice of Sleep Medicine, 6th ed. 2017. W. B. Saunders.

[27] Varvara B, Effrossine T, Despoina K, et al. Effects of Neonatal Intensive Care Unit Nursing Conditions in Neonatal NREM Sleep. Journal of Neonatal Nursing. 2016; 22(3): 115-123.

[28] Garden S, Goldson G, Hernande Z. The Neonate and the Environment, Impact on The Development. In Merenstein and Gardner's handbook of Neonatal Intensive Care. 2010.

[29] Reyhani T, Aemmi S, Sannadgol V, et al. The Effect of Creating an Artificial Night on Physiological Changes in Preterm Infants. International Journal of Pediatrics. 2014; 2(12): 407-4012.

[30] Lebel V, Aita M, Johnston C, et al. Effects of Cycled Lighting versus Continuous Near Darkness on Physiological Stability and Motor Activity Level in Preterm Infants. Advances in Neonatal Care. 2017; 17(4): 282-291. 